\title{
El Consejo Hispanoamericano de Estudiantes (1979- 1980). La juventud católica intransigente en la Guerra Fría
}

\section{The Council of Hispanic Students (1979-1980). The intransigent Catholic youth in the Cold War}

\author{
Mónica Alcántara Navarro \\ Universidad Nacional de General Sarmiento
}

\begin{abstract}
Resumen
En enero de 1979, a unos meses de iniciado el pontificado de Juan Pablo II, jóvenes universitarios identificados con el catolicismo intransigente y vinculados a organizaciones transnacionales de derechas, fundaron en la Ciudad de México el Consejo Hispanoamericano de Estudiantes (CHE). La organización estableció una agenda regional común y se propuso coordinar las actividades de los jóvenes en sus diferentes países. Un año después, en medio de las celebraciones en Argentina por el año Mariano, los integrantes del consejo se reunieron en la ciudad de Córdoba para dar continuidad a sus objetivos. En las actividades llevadas a cabo, contaron con la asistencia de autoridades eclesiásticas y destacados intelectuales católicos.

Este artículo se propone demostrar la presencia y protagonismo juvenil entre los grupos de católicos laicos integristas y de la fortaleza de las alianzas transnacionales católicas en un contexto de intensificación del anticomunismo durante la Guerra Fría.

La reconstrucción y análisis de los congresos ha sido posible a partir de la revisión hemerográfica y de archivos de inteligencia de Argentina y México. Estas fuentes han sido contrastadas con el testimonio de un militante inactivo de las organizaciones católicas mexicanas. Su narración ofreció numerosos elementos para repensar el papel de los jóvenes católicos en el periodo, además, expone las tensiones y disputas en torno a los significados y disputas sobre la juventud y la definición de los jóvenes en la sociedad.
\end{abstract}

Palabras clave

Jóvenes; católicos; intransigentes; derechas; Hispanoamérica; universidad; Historia transnacional

\begin{abstract}
In January 1979, a few months after the initiation of the John Paul II's pontificate, a group of young university students linked to the intransigent Catholicism and transnational rightwing organizations, founded in Mexico City the Council of Hispanic Students (CHE). The organization established a common regional agenda and they was proposed to coordinate the activities of young people in their different countries.

One year later, in the middle of the celebrations in Argentina for the Marian year, the members of the council met in the city of Córdoba to continue their objectives. In the activities carried out, they had the assistance of ecclesiastical authorities and prominent Catholic intellectuals.
\end{abstract}

Esta obra está sujeta a la Licencia Reconocimiento-NoComercial-CompartirIgual 4.0 Internacional de Creative Commons. http://creativecommons.org/licenses/by-nc-sa/4.0/ 


\section{El Consejo Hispanoamericano de Estudiantes (1979-1980). La juventud católica intransigente en la Guerra Fría}

This article aims to demonstrate the presence and protagonism of youth among groups of integralism lay Catholics and the strength of Catholic transnational alliances in a context of intensification of anti-Communism during the Cold War.

The reconstruction and analysis of the congresses have been possible with based on the review of the hemerographic and the intelligence archives of Argentina and Mexico. These sources have been contrasted with the testimony of an inactive militant of Mexican Catholic organizations. His narrative offered numerous elements to rethink the role of young Catholics in the period, also exposes tensions and disputes about the meanings and disputes about youth and the definition of young people in the society.

Keywords

Catholic; intransigent; young; right wing; Hispanic; University; transnational history

\section{Introducción}

El 20 de enero de 1979, días antes del arribo del Papa Juan Pablo II a la Ciudad de México, los agentes de la Dirección Federal de Seguridad dieron cuenta de una reunión realizada en la Universidad Continental, ubicada en el sur de la Ciudad de México. El encuentro recibió el nombre de Primer Congreso Internacional de Estudiantes Católicos y asistieron 300 jóvenes universitarios católicos provenientes de España, Francia, Uruguay, Brasil, Chile y Argentina. Al terminar, se estableció una agenda común en la que los asistentes acordaron la fundación del Consejo Hispanoamericano de Estudiantes (CHE) y una segunda reunión internacional. La prensa argentina registró el segundo encuentro los días 22 y 23 de octubre de 1980 en Embalse del Río Tercero, en Córdoba, Argentina. En ese congreso, los jóvenes tuvieron la oportunidad realizar un balance sobre la importancia de las universidades como espacios formadores de estudiantes católicos y la necesidad de defenderlas. El testimonio de un militante católico mexicano que hacia finales de la década de los setenta se integró a los grupos juveniles, mencionó una tercera reunión tuvo lugar en Madrid, España. La prensa de aquel país dejó asentado que integrantes del CHE se reencontraron del 10 al 12 de octubre de 1982, con una asistencia de 200 jóvenes entre los que destacaron las delegaciones de Argentina, Brasil, México y Perú. De la actividad transnacional desplegada en las décadas de los setenta y ochenta por los grupos católicos intransigentes, las reuniones del Consejo Hispanoamericano de Estudiantes se destacan por la participación y protagonismo de los jóvenes.

La historiografía sobre los jóvenes católicos identificados con las derechas en Argentina y en México ha recorrido caminos desiguales. En general, han sido menos estudiados que aquellos vinculados a las militancias de izquierda (Bohoslavsky Gomes 2016), y se les ha considerado exclusivamente como antagonistas a los movimientos progresistas o revolucionarios, lo que dificulta el análisis de sus posicionamientos políticos. Sirvan de ejemplo los trabajos de los mexicanos (Dávila 2001; González 2003) que ubican a los jóvenes católicos únicamente como oposición conservadora a las movilizaciones estudiantiles de corte progresista en la Benemérita Universidad Autónoma de Puebla. 


\section{Mónica Alcántara Navarro}

Para la historiadora Valeria Manzano (2007), estudiar a la juventud implica una distinción entre los jóvenes como actores y la juventud como categoría, por ello, los significados que se le atribuyan a esta última implican una disputa entre más de un sujeto o colectivos, en el caso del CHE, al que identifico como grupo de jóvenes católicos integristas intransigentes, esas tensiones se generaban, con la jerarquía, una multiplicidad de grupos laicos y los mismos jóvenes que a través de sus acciones intentaban construirse una identidad con funciones específicas dentro del catolicismo y que no siempre coincidía con las expectativas de los adultos. Además, el investigador Steven Mintz (2008), destaca que la categoría de juventud es definida históricamente de acuerdo al contexto, por eso, determinar quiénes son los jóvenes católicos y sus funciones en la sociedad o en las universidades, son construcciones sociales tirantes. Cabe aclarar que las propuestas de los autores mencionados no contemplan a las juventudes católicas, en el caso del trabajo de Manzano, aparecen los adultos católicos como oposición al protagonismo modernizador de la juventud de las décadas de los sesenta y setenta.

En el caso argentino Sebastián Pattin (2018) propone que los grupos de católicos laicos posteriores al Concilio Vaticano II cuestionaron fuertemente la autoridad eclesial. Tras el Concilio, la vida de la Iglesia estuvo marcada por diferencias generacionales propias de la efervescencia de la época, en donde las principales críticas venían de los jóvenes.

Generalmente, la historiografía ubica como espacios de la juventud a las universidades-de ahí que constantemente sean pensados como estudiantes- y en agrupaciones de laicos, sobre todo, en las bases juveniles de Acción Católica. Al respecto, Jessica Blanco (2011), argumentó que las clasificaciones etarias son invenciones históricas y un elemento preponderante en la construcción de identidades. Afirmó que a partir de las conclusiones del Concilio la Iglesia argentina consideró a los jóvenes fuerza de cambio privilegiada. Entre los investigadores que advirtieron los distanciamientos de los jóvenes y los adultos, destacan los trabajos de María Aspe (2007) y Omar Acha (2016). Éste último observó en la militancia masculina de ACA y sus prácticas de sociabilidad, un desajuste entre lo que él llama los modelos imaginarios construidos por la jerarquía y los adultos laicos frente a las prácticas reales de la juventud.

La mexicana María Aspe, en su estudio sobre ACM y la Unión Nacional de Estudiantes Católicos, advirtió una contradicción entre una militancia integrista, que exigía a los integrantes llevar el mensaje de Cristo a todos los ámbitos de su vida y una jerarquía que les prohibió la participación política. La autora distinguió una multiplicidad de pensamientos católicos divergentes entre lo plasmado en los estatutos de ACM y el que circulaba entre los jóvenes y conflictuaba las aspiraciones de la jerarquía.

Con menor frecuencia, otro espacio en donde son ubicados los jóvenes católicos es en la calle. La investigadora Miranda Lida analizó las prácticas del catolicismo de masas que durante la última dictadura argentina permitió que la población despolitizada y temerosa, volviera a salir. Destacó la fuerte presencia juvenil y la postura de las autoridades eclesiales al tratar de brindarles un lugar destacado, sin 


\section{El Consejo Hispanoamericano de Estudiantes (1979-1980). La juventud católica intransigente en la Guerra Fría}

embargo, la autora no problematizó sobre la relación entre adultos y jóvenes. Por su parte Estela Shindel (2005), discute la idea de la despolitización en el mismo periodo y en el caso de los católicos, propone que las peregrinaciones y el aumento en las parroquias de grupos juveniles se convirtieron en posibilidad de acción y otras formas de participación política. Cabe preguntarse cuáles fueron los lugares de organización y manifestación política de los católicos del CHE además de las universidades.

Para reflexionar sobre la militancia católica de los integrantes del Consejo, retomo las propuestas de los estudiosos mexicanos Roberto Blancarte (1994) y la ya mencionada María Aspe (2007), quienes aplicaron el concepto integrismo en sus estudios sobre la Iglesia católica mexicana y las relaciones entre la jerarquía y los grupos de laicos. Consideran que el integrismo se dirigía a la formación de católicos de tiempo completo que podían y debían incidir en todo el ámbito social para restaurar el orden social cristiano. Por otro lado, intransigencia es la oposición al liberalismo y su negación como ideología oficial de toda la sociedad moderna. Sumo las aclaraciones realizadas por Alicia Puente (2002) respecto a la delimitación de los laicos, que los define como aquellos sujetos bautizados que no han hecho una consagración especial para ingresar a la estructura eclesiástica y puede ser que no cumplan con una función institucional.

En el caso mexicano, ${ }^{1}$ destacan los trabajos comparativos y de redes sobre agrupaciones de jóvenes católicos mexicanos, pertenecientes a la Organización Nacional el Yunque ${ }^{2}$ y los jóvenes nacionalistas argentinos nucleados bajo la denominación Tacuara. Los investigadores Mario Santiago (2016) y Luis Herrán (2015), contribuyeron a la comprensión del anticomunismo y las acciones de la derecha a nivel continental. Siguiendo a otra agrupación católica intransigente, los Tecos, ${ }^{3}$ la historiadora Mónica López (2010) estableció sus mecanismos de contacto y articulación en una de las redes transnacionales anticomunistas de derechas, la

\footnotetext{
${ }^{1}$ Para el caso Mexicano, unos meses después de la llegada al poder del Partido Acción Nacional (PAN) en el año 2000, en el diario Reforma se publicó un artículo sobre la presencia y monopolización del partido por parte de un grupo reservado-secreto integrado por católicos de extrema derecha, la organización referida era el Yunque. La revelación destapó el interés mediático por las derechas mexicanas, hasta entonces, habían sido estudiadas de forma aislada en los trabajos del periodista Manuel Buendía. El creciente interés por las derechas se visibiliza en los trabajos del periodismo de investigación mayoritariamente concentrados en denunciar al Yunque. Desafortunadamente, el interés académico entre los historiadores no acompañó ese auge periodístico. A mi consideración, la coyuntura política que despertó el interés en la derecha mexicana terminó por constreñir el desarrollo historiográfico y nos llevó al análisis de las escasas posibilidades de las derechas, es decir, al Yunque y a organizaciones vinculadas. En comparación al desarrollo historiográfico argentino sobre las derechas, el mexicano resulta escaso.

${ }^{2}$ Las ramas juveniles del Yunque son: Frente Universitario Anticomunista (FUA) y el Movimiento Universitario de Renovadora Orientación (MURO).

${ }^{3}$ El origen de la organización se ubica en el año 1935 en la Universidad Autónoma de Guadalajara, entre sus objetivos destacaron frenar el avance comunista en la universidad y se convirtió en un grupo de choque compuesto por jóvenes católicos. Al igual que el Yunque, se le ha ubicado entre las extremas derechas mexicanas.
} 
Confederación Anticomunista Latinoamericana ${ }^{4}$ y sus acciones durante la guerra fría. La vinculación entre las derechas mexicanas, las suramericanas, específicamente con sus pares argentinos, son propuestas historiográficas recientes y escasas. Las investigaciones mencionadas, enfocaron su análisis en identificar a los sujetos, intelectuales o dirigentes, participantes sin problematizar el hecho de que eran jóvenes católicos.

Este artículo propone que el análisis de los congresos del Consejo Hispanoamericano de Estudiantes permite ubicar a los jóvenes católicos como grupo etario diferenciado de los adultos que se adhirieron a las redes trasnacionales anticomunistas con una agenda propia y en un espacio de acción ceñido al ámbito universitario. ${ }^{5}$

Sobre las diferencias ideológicas o doctrinarias, antepusieron los elementos comunes; su catolicismo intransigente, anticomunista, hispanista, tomista y sobre todo auto-reconocimiento como jóvenes católicos. En el caso mexicano, los católicos intransigentes se propusieron instaurar el reino de Dios en la tierra, por su parte, los católicos tradicionalistas argentinos se enfocaron en consolidar la nación católica. Las reuniones del CHE ejemplifican la posibilidad de coincidencia y establecimiento de un proyecto regional de recristianización de la sociedad. Considero que el análisis de su militancia requiere el dialogo entre los estudios historiográficos sobre la juventud y los estudios sobre las derechas, en los que la juventud católica de derechas ha sido escasamente problematizada. Para completar la investigación, es necesario considerarlos en perspectiva transnacional que permita dar cuenta de sus vínculos y estrategias regionales.

La primera parte del artículo hace un recuento de los sujetos e instituciones relacionadas en la fundación del CHE en México, así como un breve recorrido por los hechos relevantes de 1979. Ello contribuye a delimitar las dinámicas de trabajo a partir de las cuales se organizaron los jóvenes en cuestión. La segunda parte se concentra en la reunión del consejo realizada en Córdoba, junto a otras acciones del catolicismo tradicionalista. El trabajo cierra con un balance sobre las representaciones y tensiones en torno a la militancia de los jóvenes católicos en las fuentes.

Las fuentes utilizadas para el análisis de las acciones de los jóvenes son publicaciones periódicas y revistas mexicanas y argentinas; la información de las tarjetas y expedientes elaborados por los agentes de la Dirección Federal de Seguridad y la Dirección de Inteligencia de la Policía de la Provincia de Buenos Aires

\footnotetext{
4 Para una propuesta sobre las familias anticomunistas de derechas y sus articulación en redes transnacionales: (Bohoslavsky 2017; Rostica 2017; Bohoslavsky y Vicente, 2014).

${ }^{5}$ Hasta el momento, la investigadora Laura Rodríguez ha presentado el único trabajo académico en el que se ha mencionado al Consejo Hispanoamericano de Estudiantes sin que éste sea el objeto central de su investigación. Ha sido tema secundario en sus múltiples trabajos sobre la actuación de sectores del catolicismo nacionalista y tradicionalista en las universidades argentinas durante la última dictadura. Sobre la autora se pueden consultar los trabajos: )Rodríguez 2011, 2015, 2016).
} 


\section{El Consejo Hispanoamericano de Estudiantes (1979-1980). La juventud católica intransigente en la Guerra Fría}

(DIPBA) y el testimonio de un militante inactivo del catolicismo intransigente en México. ${ }^{6}$

\section{La fundación del Consejo Hispanoamericano de Estudiantes y la primera visita del papa Juan Pablo II (México, 1979)}

El anuncio de la primera visita del papa Juan Pablo II a México en enero de 1979 desató fuertes polémicas entre diversos sectores políticos del país para establecer si la presencia del pontífice implicaba o no una violación al Estado laico. ${ }^{7}$ En aquellos años, el país atravesaba una crisis económica y de legitimidad ante el desgaste del consenso que mantuvo en el poder por varias décadas al Partido Revolucionario Institucional. José López Portillo llegó como candidato único a la presidencia en 1976 (Cedillo 2010; Héctor Aguilar/Lorenzo Meyer, 2000 ; Córdova 1979; Fernández 1978).

Entre los sectores opositores a los regímenes posrevolucionarios y que habían expresado su rechazo a López Portillo, incluso antes de ocupar la presidencia, se encontraban los jóvenes católicos intransigentes militantes de las estructuras públicas de los Tecos y del Yunque. De origen común, ésta última de carácter secreto y anticomunista, fue fundada en el estado de Puebla en el año de 1953 y al finalizar la década de los setenta, ya había atravesado por una importante fase de expansión por el territorio nacional, complejizando su estructura, activando grupos que funcionaran públicamente y fortaleciendo sus vínculos internacionales.

Sin embargo, en los años posconciliares, tuvieron importantes diferencias doctrinarias con los Tecos, cuando éstos desconocieron la autoridad del papa acusándolo de judío infiltrado, lo que les valió la excomunión de su guía espiritual, el sacerdote José Manuel Figueroa. Por otro lado, los militantes del Yunque, aunque desaprobaron las conclusiones del Concilio, se mantuvieron fieles a la autoridad del Papa. La escisión no estuvo exenta de agresiones entre sus militantes, lo que llevó a las organizaciones al quiebre definitivo y a la enemistad. Por esa razón, su articulación transnacional se dio en distintas redes anticomunistas (López 2010).

\footnotetext{
${ }^{6}$ El testimonio identificado como Directivo fue un joven militante católico entre al finalizar la década de 1970. Inició su militancia en los grupos públicos del Yunque, primero en el MURO, luego en el CNE y se vinculó a las actividades del Consejo Hispanoamericano de Estudiantes. Directivo (seudónimo). Entrevista realizada por la autora, Ciudad de México, 8/06/2015.

7 Desde la promulgación de las Leyes de Reforma, decretadas por los liberales radicales tras su ascenso al poder en 1855, la Iglesia en México fue perdiendo terreno político y económico. La Constitución de 1857 decretó en su artículo $3^{\circ}$ que la educación quedaba libre de coacción y se otorgó a todos los ciudadanos el derecho de expresar y publicar cualquier opinión o doctrina que adoptasen. La Constitución de 1917, emanada de la Revolución Mexicana, resultó una embestida aún mayor al poder de la Iglesia. En el artículo $3^{\circ}$ quedó establecida una educación laica y prohibía a las corporaciones religiosas o ministros de culto que se encargaran de las escuelas. El conflicto por el control educativo entre el Estado, la jerarquía y los grupos laicos, es una de las disputas que atraviesa el siglo XX mexicano.
} 
La visita del Papa a México se realizó en el marco de su primera gira por países latinoamericanos e incluyó República Dominicana y las Bahamas. En México, recorrió los estados de Oaxaca, Nuevo León, Jalisco y Puebla, en donde tuvo a cargo la inauguración de la III Conferencia Episcopal Latinoamericana cuyo tema fue Evangelización en el presente y futuro de América Latina. También pasó por la Ciudad de México, en la que ofició misas en la catedral metropolitana y en la Basílica de Guadalupe.

Durante la visita del papa a México, los jóvenes católicos manifestaron públicamente su fe y repudio a los gobiernos posrevolucionarios. Sin embargo, el desacuerdo con el régimen ya había sido expuesto años antes, una de las expresiones de descontento que destaco por su nutrida asistencia fue una concentración llamada Primer Encuentro Nacional Juvenil, se llevó a cabo en agosto de 1975 en Naucalpan de Juárez, Estado de México. La organización estuvo a cargo de las organizaciones juveniles vinculadas a las estructuras públicas del Yunque (Santiago 2012; Alcántara 2016), como el Consejo Nacional de Estudiantes (CNE). ${ }^{8}$ La prensa mexicana registró algunos fragmentos de los discursos de los jóvenes, destaca una lectura de la historia de México en la que se construyen como oposición juvenil al partido único, al tiempo que denuncian reiteradamente como juventudes silenciadas, en lucha y oposición permanente y comprometidos a "trabajar por México para hacer una nación libre y justa". 9

Unos días antes del arribo del pontífice, el 20 de enero de 1979, el CNE y el Movimiento de Unificación Estudiantil, organizaron el Primer Congreso Internacional de Estudiantes Universitarios Católicos. Realizado en la Universidad Intercontinental, ubicada al sur de la Ciudad de México. Los mexicanos recibieron delegados de grupos católicos de Francia, España, Argentina, Brasil, Chile, Uruguay, Colombia y Perú. Acudieron observadores del Colegio Lasalle y de la Universidad Iberoamericana. ${ }^{10}$ De acuerdo a la información de la prensa y de la DFS, asistieron 300 jóvenes entre nacionales y extranjeros. El evento abrió con discursos de bienvenida y la lectura de encíclicas, ${ }^{11}$ para dar paso a las ponencias de los delegados extranjeros ${ }^{12}$ en las que predominaron temas que consideraron problemáticas universitarias, por ejemplo, la subversión y la masificación.

\footnotetext{
${ }^{8}$ El Consejo Nacional de Estudiantes fue fundado meses antes en la Universidad de Querétaro, uno de sus objetivos más importantes era coordinar las actividades y reuniones nacionales de otras organizaciones de jóvenes católicos, así como vigilar el cumplimiento de los acuerdos alcanzados en cada evento. El CNE forma parte de la estructura del Yunque.

9 "Los jóvenes católicos lucharán contra las doctrinas que denigran al hombre". En: El Universal, 18 de agosto de 1975.

10 Agentes de la Dirección Federal de Seguridad y periodistas mexicanos estuvieron presentes en la reunión y proporcionaron información relevante y breves reconstrucciones de lo sucedido, sin embargo, no especifican el nombre de los observadores asistentes o las organizaciones católicas a las que pertenecían los jóvenes extranjeros.

${ }^{11}$ Se revisaron las encíclicas Militantis Ecclesiae, Humani Génesis, Divini Illius Magistri, Quadragesimo Anno, Divini Redemptoris

${ }^{12}$ Cabe aclarar que ni en los documentos de la DFS, ni en prensa mexicana o argentina, se identificaron las organizaciones a las que pertenecían los jóvenes en sus respectivos países.
} 


\section{El Consejo Hispanoamericano de Estudiantes (1979-1980). La juventud católica intransigente en la Guerra Fría}

Entre las participaciones registradas, se encuentran la intervención del uruguayo Heraclio Labandera, quien denunció que la "subversión había llegado hasta las universidades llena de falsas ideas para lavar el cerebro de los jóvenes, corrompiendo la misión de la universidad" y por eso fue necesario que "nuestros países, más de una vez, hayan recurrido a las fuerzas armadas como salvaguarda de los valores permanentes."13

El argentino Pablo Garat ${ }^{14}$ advirtió que se estaba atentando contra la ira de Dios y rechazó lo que llamó "teorías ateas y antropocéntricas" (haciendo referencia al liberalismo, marxismo, freudismo, freirerismo, racionalismo y evolucionismo) porque sus explicaciones contravenían "el orden natural” y como jóvenes católicos debían tener muy claro que "o se está con Cristo o se está contra él (es) es nuestra obligación ser soldados de Cristo. ${ }^{15}$ El español Vicente José Fernandez Burgueño declaró que "la universidad presenta unos fines concretos y la idea medieval era la de acercarse lo más posible a la verdad [...] (y) este valor está en crisis desde hace mucho tiempo". ${ }^{16}$ Su compatriota, Javier Urcelay Alonso, ${ }^{17}$ enfatizó que los jóvenes en su país deseaban que la universidad naciera, creciera y se enriqueciera al calor de la Iglesia, porque eso era cien veces preferible a la inspección laica e incompetente de directores y ante la situación "no hay combate más excelso que aquél en que el soldado tiene que ser a la vez salvador y civilizador".18

Finalmente, se registraron las palabras del joven francés Jean-Paul Arnaud, quien se refirió a las movilizaciones estudiantiles de 1968 calificándolas como "espectáculo vergonzoso de todas las universidades en huelga durante varios meses [...] y está siempre en la memoria [...] (por eso) los jóvenes franceses hemos utilizado todos los medios que se requieran para decir no a la revolución". ${ }^{19}$ Además prevalecieron las

\footnotetext{
13 Ignacio Ramírez, “Congreso de la Joven derecha. Dictadura militar, sí; revolución, no”, en: Proceso, No. 117, 29/01/1979, p. 16-17.

${ }_{14}$ Abogado y docente de grado y posgrado de la materia derecho constitucional en la Universidad Católica Argentina. Es identificado como presidente de la organización Civilidad e integrante de la Fundación Nuevas Generaciones (ambas organizaciones ligadas a Ciudad Católica), entre sus funciones destacan la organización de cursos dirigidos a los jóvenes. Recientemente formó parte del grupo de veintidós expositores en la última audiencia en el senado sobre el debate por la Ley de Interrupción voluntaria del embarazo. Se pronunció en contra de la iniciativa y declaró que: "estamos transformando un delito en un derecho y esto no lo dice el doctor Garat sino el proyecto aprobado en Diputados", finalizó su exposición citando a la madre Teresa de Calcuta diciendo: "no los aborten, no las aborten, dénselos a todos aquellos que tienen amor para recibirlo". Las intervenciones del debate pueden ser consultadas en: http://www.senado.gov.ar/prensa/16591/noticias;

15 Ignacio Ramírez, "Congreso de la Joven derecha..." op. cit.

16 Ibidem.

17 Nacido en Madrid, licenciado en Ciencias Biológicas por la Universidad Complutense. Ha realizado trabajos de investigación histórica en los que destacan los temas sobre carlismo, guerras civiles en el siglo XX. Es autor de ensayos sobre la Teología de la Liberación, avances científicos, medios de comunicación y familia. Fue candidato al senado por las provincias de Castellón y de Avala y miembro del Comité de Bioética español ante la UNESCO.

${ }^{18}$ Ignacio Ramírez, "Congreso de la Joven derecha...” op. cit.

19 Ibidem.
} 
declaraciones fatalistas que alertaban que el mundo estaba en crisis y que las universidades estaban riesgo por la "infiltración marxista." 20

Los reunidos concluyeron que los problemas tenían un origen común en el alejamiento de las enseñanzas de la Iglesia. Una de sus principales propuestas era incluir de manera obligatoria la cátedra de Teología en todas las universidades hispanoamericanas.

Al finalizar del encuentro, redactaron un documento con las conclusiones y acordaron la fundación del Consejo Hispanoamericano de Estudiantes, que seguramente funcionó como estructura de coordinación de numerosas organizaciones de jóvenes católicos de los países ahí reunidos. El resumen de las conclusiones se redactó de la siguiente manera:

1) La fundación del Consejo Hispanoamericano de Estudiantes.

2) Adicción fiel a la Santa Madre Iglesia y acatamiento, como obligación para su conducta la voz de los pastores.

3) Instituirse nuevamente la materia de teología en las Universidades

4) Justificación de la intervención de las fuerzas armadas para salvaguardar los valores permanentes en una nación.

5) Oposición a la politización de las universidades.

6) Que los centros de estudios universitarios vuelvan a adoptar la doctrina social de la Iglesia para que ésta haga que se resuelvan los problemas de desempleo y violencia en el mudo. ${ }^{21}$

Los jóvenes reunidos eran conscientes de la proximidad del arribo del Papa y la inauguración de la III CELAM, por lo que se plantearon "hacer escuchar su voz", entregando al obispo tomista y rector de la Universidad Católica Argentina, Octavio Derisi, ${ }^{22}$ un paquete de documentos que incluían las transcripciones de las conferencias y las conclusiones, para que expusiera su contenido ante los asistentes de la Conferencia Episcopal. ${ }^{23}$ El rector Derisi trataría de mantenerse cercano y guiar las actividades de los jóvenes, sin embargo, ya había participado de algunas

\footnotetext{
${ }^{20}$ AGN, DFS, CNE, Exp. 15-13-79, L-1, F-155-157. La historiadora Laura Rodríguez afirma que la Coordinadora Universitaria Nacional (CUN) se cuenta entre los miembros fundadores del CHE y el grupo estaba encargado de articular las organizaciones de universitarios católicos de distintas provincias argentinas como Buenos Aires, Santa Fe, Mendoza, Entre Ríos, Corrientes y Salta. En; Laura Rodríguez, "La 'subversión científica” op. cit.

${ }^{21}$ Hasta el momento, las fuentes consultadas no permiten tener certeza de quienes redactaron el documento. AGN, DFS, CNE, Exp. 15-13-79, L-1, F-155-157

${ }^{22}$ Fue el primer rector de la Universidad Católica Argentina desde su fundación hasta 1980 y presidente de la Organización de Universidades Católicas de América Latina y el Caribe (ODUCAL). Educado como teólogo católico y filósofo laico, se convirtió en una de las cabezas del tomismo en argentina durante la segunda mitad del siglo XX, por lo que impulsó en las universidades el pensamiento tomista y se le considera formador de jóvenes católicos. Mantuvo estrechos vínculos con el Vaticano y en 1953 fue designado prelado doméstico de Pío XII, con derecho al tratamiento de monseñor. En 1979 se encontraba en México como parte de la delegación argentina asistente a la III CELAM.

${ }^{23}$ LA DFS ya no registra si en las reuniones en Puebla se expusieron o no, las aportaciones del CHE.
} 


\section{El Consejo Hispanoamericano de Estudiantes (1979-1980). La juventud católica intransigente en la Guerra Fría}

tensiones con estudiantes de la Universidad católica por intentar tutelar o desaprobar su militancia política ${ }^{24}$

Cipriano Calderón, ${ }^{25}$ director de la edición en español del diario L'Obsservatore Romano. $^{26}$ El CHE se comprometió a mantenerse activo y encargarse del cumplimiento continental de las conclusiones generadas en la ceremonia fundacional.

El papa llegó a México el 26 de enero de 1979. Dedicó varios discursos a los jóvenes destacando su energía y capacidad transformadora, seguramente, los que más impacto causaron a los integrantes del CHE, fueron los dirigidos a los estudiantes católicos cuando dijo:

¿qué puede esperar el mundo universitario católico mexicano y latinoamericano de las palabras del papa? [...] que la universidad católica debe encontrar su significado último y profundo en Cristo, en su mensaje salvífico [...] debe ser un ámbito en donde el cristianismo sea vivo y operante. 27

En su testimonio, Directivo, ${ }^{28}$ ex militante del CHE, recordó que miles de jóvenes salieron las calles para ver y escuchar a Juan Pablo II:

para nosotros fue una cosa impresionante, nunca había venido un Papa a

México [...] el hecho de que hubiera venido era súper importante y participamos [...] y ahí estuvimos, claro, entonces, estar en las calles, participar [...] nos quedamos toda la noche para ver otra vez pasar al Papa, fue una cosa muy bonita. ${ }^{29}$

Las palabras del Papa, reafirmaron en los jóvenes militantes la certeza de su protagonismo y que sus acciones se encaminaban por el camino correcto. Los integrantes del CHE se reencontraron un año después, en Córdoba Argentina.

\section{El Consejo Hispanoamericano de Estudiantes en Córdoba}

\footnotetext{
24 En el expediente de la Universidad Católica generado por la Dirección de Inteligencia de la Provincia de Buenos Aires, quedó asentado que durante una asamblea estudiantil en las instalaciones de la universidad, moseñor Derisi declaró su desaprobación las actividades estudiantiles, reiteró la prohibición existente en las universidades para realizar actos políticos y negó que esos jóvenes representaran a las mayorías estudiantiles.

${ }^{25}$ En los años del Concilio Vaticano II ejerció una intensa actividad periodística como jefe de la sección de la Oficina de Prensa del concilio, por lo que prácticamente asistió a todas sus sesiones. Numerosos lectores pudieron seguir aquel acontecimiento por sus crónicas y artículos de opinión. En 1968 el papa Pablo VI lo nombró director de la edición en español de L'Osservatore Romano. Para el año de 1979, además de asistir a la fundación del CHE, se convirtió en una figura cercana a Juan Pablo II.

${ }^{26}$ Eduardo Arvizu, "Ajenos a la CELAM los aspectos políticos y Económicos. Derisi", El Universal, 22/01/1979, p. 10.

27 Discurso del Santo Padre Juan Pablo II a los Universitarios católicos de México, 31 de enero de 1979, en:http://w2.vatican.va/content/john-paul-ii/es/speeches/1979/january/documents/hf_jpii spe 19790131 messico-guadalupe-univ-catt.html; [Consultado: 1/11/2018].

28 Directivo op. cit.

29 Íbidem.
} 
En el contexto de la primera visita del papa Juan Pablo II a México y los conflictos limítrofes entre Argentina y Chile por el Canal del Beagle, casi al finalizar el año de 1979, el episcopado argentino declaró la celebración de un año Mariano. Lo que intensificaría las movilizaciones masivas del catolicismo y en el que la prensa destacó la fuerte presencia y participación juvenil. Entre todos los actos llevados destaca el II Congreso Mariano, celebrado del 8 al 12 de octubre en Mendoza, ${ }^{30}$ al que asistieron personajes de la jerarquía vinculados al papa Juan Pablo II, por ejemplo, el cardenal Paolo Bertoli, designado parte del grupo de negociación vaticana, quien le entregó al general Videla una carta del Papa en donde expresaba "la importancia que el Vaticano otorga al evento religioso que se efectuará en Mendoza."31 Durante la clausura del congreso celebrada en el estadio mundialista, el camarlengo ofició la misa y leyó un mensaje del Papa a los asistentes. Estuvo presente el general Videla que dio el discurso de clausura.

A diferencia de México, en donde el establecimiento del estado laico limitó la injerencia de la jerarquía y de sectores católicos laicos en el plano educativo, durante la dictadura de Videla, los católicos tradicionalistas interesados en la educación universitaria establecieron acuerdos con el ministro de Cultura y Educación Juan Rafael Llerena Amadeo, ${ }^{32}$ entre sus logros destacó la instauración de la asignatura de Formación Moral y Cívica. ${ }^{33}$ Ante la fuerte presencia de sectores tradicionalistas, las universidades nacionales no permanecieron ajenas a estos actos, declararon su adhesión al congreso y procuraron otorgar a los docentes y estudiantes las facilidades para asistir sin tener consecuencias administrativas por sus faltas. ${ }^{34} \mathrm{La}$ secretaría del Ministerio de Cultura y Educación informó que los asistentes tendrían que presentar un aval de sus respectivas diócesis para justificar sus ausencias. ${ }^{35}$

En el transcurso de los preparativos para la celebración del congreso mariano, en los que destacó una intensa participación juvenil, el obispo Jorge Cassaretta, manifestó su preocupación por el impacto negativo de los acontecimientos nacionales sobre los jóvenes y la falta de "maestros que les muestren el camino", mientras que los "falsos profetas" los llevaron a ser "arrastrados por el camino de la violencia". ${ }^{36}$ En el mismo sentido se expresó el ex rector de la Universidad Católica de Córdoba, sacerdote jesuita Jorge Fourcade, quien manifestó su preocupación al

\footnotetext{
30 Un relato pormenorizado en la celebración en el estadio en Miranda Lira op cit.

31 "Videla recibió al enviado del Papa" en: Los Principios, 7/10/1980, p. 4.

${ }^{32}$ Abogado católico, defensor e impulsor de la enseñanza privada, en especial del nivel universitario. Fue profesor titular de la Facultad de Derecho de la UCA y de la Universidad el Salvador. No logró que se volviera a enseñar educación cristiana en las escuelas públicas. En 1978 fue nombrado ministro de Cultura y Educación. En el ámbito internacional, ocupó el puesto de presidente de la comisión Ejecutiva Permanente para la Educación, la Ciencia y la Cultura, de pendiente de la OEA.

33 El ministro defendió la materia bajo el argumento de la necesidad de reforzar los contenidos morales de la educación nacional (Cersósimo, 2014).

${ }^{34}$ La Universidad de Salta recomendó incluso otorgar asueto docente y administrativo conforme a las normas. Resolución del Rectorado de Salta No 508-80

35 "Adhesión al Congreso Mariano", La Voz del Interior, 7/10/1980, p. 9.

36 "El obispo de Rafaela dijo que los jóvenes necesitan de testimonios auténticos", La Voz del interior, 9/10/1980, p. 9.
} 


\section{El Consejo Hispanoamericano de Estudiantes (1979-1980). La juventud católica intransigente en la Guerra Fría}

declarar que "el joven universitario hoy está todavía un poco ausente en el interés por los problemas argentinos [...] un decaimiento, una apatía general"37

La reunión de los jóvenes católicos del CHE recibió el nombre de II Congreso Internacional de Estudiantes Católicos, Presente y futuro de la Universidad y fue declarada de interés nacional. ${ }^{38}$ Formó parte de un ciclo de congresos realizado en el complejo turístico de Embalse de Río Tercero en Córdoba, que abarcaron desde el 21 al 27 de octubre. ${ }^{39} \mathrm{Al}$ concluir la reunión de los jóvenes se inauguró el congreso La Hispanidad: la nación cristiana a través de su vertiente hispanoamericana, con asistencia internacional en la que predominaron los adultos.

Seguramente, el CNE estuvo encargado de la coordinación de la delegación mexicana y en Argentina, la organización estuvo a cargo de la Coordinadora Universitaria Nacional. ${ }^{40}$ Contó con la presencia de 200 asistentes entre delegados nacionales y extranjeros. Las ponencias presentadas fueron: La proletarización universitaria (de México); La subversión científica (de Argentina), La docencia universitaria (Perú); La investigación Universitaria (España); El gremialismo universitario (Chile); La participación estudiantil (Uruguay). Entre los ponentes destacados se mencionan a los Doctores Felix Adolfo Lamas ${ }^{41}$ y Bernardino Montejano, ${ }^{42}$ quienes tuvieron a su cargo dos clases magistrales referidas a El tomismo en la reconstrucción del ser universitario y la restauración universitaria. Otra de las personalidades destacadas que estuvieron presentes, fue el sacerdote Octavio Derisi. ${ }^{43}$ De modo similar a las dinámicas de trabajo del primer Congreso, se redactó un documento con las

\footnotetext{
37 “Quizás hay temores en la juventud, o falta de causes para que pueda participar”, La Voz del interior, $17 / 10 / 1980$, p. 7.

38 Decreto No. $1830 / 80$ P.E.N.

39 Un año antes, se realizó en II Congreso Mundial de Filosofía Cristiana, también en Embalse del Río Tercero. A este congreso también asistió monseñor Octavio Derisi. Este acontecimiento muestra ya se había echado a andar una estructura logística y también fue declarado de interés nacional por el presidente de facto Videla. Entre los asistentes, hubo delegaciones de España, Francia, Italia, Brasil, México, Estados Unidos, Chile, Portugal, Polonia, Venezuela. La organización corrió a cargo de la Asociación Católica Interamericana de Filosofía y la Sociedad Internacional Tomista.

40 La Coordinadora articuló organizaciones universitarias católicas de provincias como: Buenos Aires, Santa Fe, Mendoza, Entre Ríos, Corrientes y Salta. Laura Rodríguez, "La 'subversión científica" op. cit.

41 Licenciado en Derecho por la Universidad Católica de Rosario, obtuvo su doctorado en la UCA. universidad de la que más tarde sería docente e investigador, al igual que en la UBA. Perteneció al Movimiento Unificado Nacionalista Argentino. En la década de los ochenta fundó el Instituto de Estudios filosóficos Santo Tomás de Aquino en Mar del Plata (Orbe, 2016).

42 Defensor del hispanismo y profesor de filosofía del derecho en la UCA

43 Entre las universidades que hicieron llegar su auspicio y adhesión, destacan los siguientes centros universitarios: Nacional de Buenos Aires, Universidad Católica de Argentina, Universidad Católica de Salta; Universidad Nacional de Rosario; Universidad Nacional de San Luis; Universidad Nacional del Litoral; Universidad Nacional de Tucumán, Universidad Nacional de la Plata; Universidad Nacional de Jujuy, Universidad Nacional de Salta, Universidad Nacional de Catamarca, Universidad Nacional de Cuyo, Universidad Católica de Santiago del Estero; Museo Social Argentino; Argentina John F. Kennedy; "Reunión Internacional de Universitarios Católicos", Los Principios, 23 /10/1980, p.6; "Programaron el II Congreso Internacional de Estudiantes Universitarios Católicos", La Voz del interior, 21/10/1980, p. 9.
} 
conclusiones obtenidas a partir de las discusiones generadas después de las conferencias, que llamaron La subversión científica. ${ }^{44}$

Sin embargo, la reunión de los jóvenes no recibió la misma atención que el Congreso Internacional de Filosofía Cristiana nombrado La Hispanidad: la nación cristiana a través de su vertiente hispanoamericana, que fue organizado y convocado por el Instituto de Promoción Social Argentina (IPSA) ${ }^{45}$ y la Fundación Pacinter. ${ }^{46}$ Se registraron 500 asistentes entre teólogos, historiadores y economistas de prestigio internacional y fue declarado de interés nacional. ${ }^{47}$ Los presentes se dedicaron a "reflexionar sobre la realidad humana y espiritual del conjunto de pueblos que hablan castellano en el mundo y que constituyen una suerte de última reserva del mundo occidental". ${ }^{48}$ El programa de trabajo se compuso de 21 ponencias y 10 foros de trabajo. Algunos de los temas fueron: Esencia de la nación hispánica; la hispanidad y su proyección político-cultural en el mundo contemporáneo; El potencial económico de la Hispanidad; la revitalización de la nación hispana; Hispanoamérica y los principios de la política cristiana; La identidad hispanoamericana; Elementos estratégicos para la defensa de Hispanoamérica; Elementos subversivos de las superurbes en Hispanoamérca; Elementos totalitarios de los partidos políticos Hispanoamericanos; Hispanoamérica en las esperanza de la Cristiandad.

Entre la lista de asistentes se encontraban destacados sacerdotes y catedráticos del catolicismo intransigente y probablemente con vínculos previos entre las redes anticomunistas. Venían de Chile, Bolivia, Uruguay, Perú, Estados Unidos, México, Venezuela, Paraguay, España y Francia. Algunos nombres que quedaron en la prensa $^{49}$ fueron: "el Dr. Juan Antonio Widow (Valparaíso); ${ }^{50}$ Dr. Alberto Caturelli

\footnotetext{
${ }^{44}$ En el documento denunciaron la "infiltración marxista" en las universidades e instituciones como UNESCO, CLACSO y FLACSO. Consideraban que uno de los principales problemas en las instituciones educativas era que "caminaban apartados del Orden Natural y Cristiano". Mientras que FLACSO y CLACSO expandían "el cáncer revolucionario por América Latina. Denunciaron por "marxistas" a intelectuales como Gino Germani, Francisco Urondo, Rodolfo Puiggrós, Enrique Flores Cano, Elizabeth Jelin. Las conclusiones del II Congreso organizado por el CHE fueron tomadas del artículo de Laura Rodríguez “La subversión” op. cit.

${ }^{45}$ La nota de prensa aclara que "IPSA es una organización de laicos inspirada en la doctrina social de la Iglesia católica, opuesta a las diversas formas de totalitarismo moderno y de la subversión anticristiana y tiene como fin iluminar con sana doctrina la acción concreta" En "Congreso internacional sobre la Hispanidad", Los Principios, 11/10/1980, p. 6. Entre sus fundadores se encuentran figuras como Carlos Sacheri, Antonio Caponnetto y Roberto Pincemin. El grupo de católicos integristas Ciudad Católica, se encargaba de los congresos de IPSA. El congreso de la Hispanidad se considera el VII organizado por IPSA, Laura Rodríguez, "La suvbersión" op. cit.

${ }^{46}$ Sus actividades fueron consideradas de interés nacional por el decreto $\mathrm{N}^{\circ} 1764 / 79$. Realizó reuniones y congresos periódicamente desde el año 1969, en los que brindaba asesoramiento a universidades públicas y privadas (El documento de la Universidad no aclara qué tipo de asesoramiento) Resolución del rectorado de la Universidad de Salta $N^{\circ}$ 509-80. Hasta el momento, no se han localizado mayores referencias de dicha organización.

47 Decreto P.E.N. No. $1586 / 80$

48 "Congreso internacional sobre la Hispanidad", Los Principios, 11/10/1980, p. 6.

${ }^{49}$ Ibidem.

${ }^{50}$ Discípulo del sacerdote Osvaldo Lira. Licenciado y profesor en filosofía por la Universidad Católica de Valparaíso, de la que después sería titular de cátedra Metafísica y Filosofía Política, de la misma universidad. Obtuvo el Doctorado en la Universidad Complutense de Madrid con la tesis, La Quarta Via de Santo Tomás, en 1968, bajo la dirección de Antonio Millán Puelles. Considerado uno de los
} 


\section{El Consejo Hispanoamericano de Estudiantes (1979-1980). La juventud católica intransigente en la Guerra Fría}

(Córdoba); Dr. Federico Ibarguren (Buenos Aires); Dr. Bernardo Montejano (Buenos Aires); prof. Rubén Calderón Bouchet (Mendoza); Dr. Vicente Ugarte del Pino (Lima); ${ }^{1}$ Dr. Federico Wilhemsen ${ }^{52}$ (Dallas); Dr Julián Gil de Sagredo Arrivas (Granada); Dr. Diego Ferreiro (Montevideo); Lic. Carlos Podestá (Asunción); Roberto Brie ${ }^{53}$ (Buenos Aires); Arq. Federico Muggemburg (México); ${ }^{54}$ Dr. José Pereda Crespo (Puebla); 55 Dr. Sergio Tapia (Lima); Dr. Jean Ousset (París); ${ }^{56}$ Dr. Martín Gutierrez (Montevideo); Edgardo y Enrique Díaz Araujo, ${ }^{57}$ Calderón Bouchet (Argentina).

El rectorado de la Universidad de Salta (en respuesta a la solicitud de adhesión de IPSA), declaró su auspicio al Congreso Internacional sobre Hispanidad, debido a que "dicha convocatoria hace referencia a la Nación Cristiana en su particularidad hispanoamericana [...] (incluyendo los elementos) que nos definen como portadores de la civilización occidental y cristiana". 58 Los asistentes propusieron que el reforzamiento de la identidad hispanoamericana permitiría un análisis regional de aspectos socioeconómicos y culturales de la región, así, las conclusiones obtenidas

referentes del tradicionalismo católico en Chile“. Es fundador de la revista Tizona, en: http://www.larramendi.es/i18n/consulta aut/registro.do?id=3572

51 Formó parte de las redes internacionales establecidas por el grupo Ciudad Católica. Laura Rodriguez "La subversión” op. cit.

52 Colaborador en la revista Verbo. (Rodríguez y Barbarito, 2011). Católico tomista de origen estadounidense, radicó en España en donde estableció contacto con sectores carlistas y tradicionalistas, a su regreso a Estados Unidos, fue profesor de la Universidad Católica de Dallas hasta su muerte, ocurrida en el 1996, Miguel Ayuso, "In memoriam. Frederick Wilhelm". Verbo, No. 345346.

53 Abogado de la Facultad de Derecho y Ciencias Sociales de la Universidad de Buenos Aires (UBA), Doctor en Filosofía por la universidad de Barcelona. Ha sido secretario general de la Universidad, Decano Interino y rector de la Universidad Católica de la Plata.

54 Arquitecto católico y militante del Partido Acción Nacional, es considerado parte del grupo de jóvenes fundadores de la estructura del Yunque y dirigente nacional del MURO. A partir de 1969 es ubicado participando en congresos sobre educación y juventud. En 1975, el Yunque intervino en las elecciones de la Unión Nacional de Padres de Familia, colocándolo como vicepresidente. Edgar González, Muro, memorias y testimonios, 1961-2002, Puebla, Gobierno del Estado de Puebla/Benemérita Universidad Autónoma de Puebla, 2003, p. 400; Mario Santiago, Anticomunismo católico. op. cit; El periodista Álvaro Delgado recoge el testimonio identificado como Luciano Ruiz Chávez quien afirmo que el militante que viajaba a España y estableció contacto con Ciudad Católica fue, Federico Muggenburg. Álvaro Delgado, El ejército de Dios. Nuevas revelaciones sobre la extrema derecha en México, Plaza Janés, Ciudad de México, 2004.

55 Fue alumno de la Facultad de Medicina de la UNAM y militante del MURO. En 1967 los jóvenes muristas emprendieron una campaña de desprestigio contra autoridades y profesores de la universidad y se declararon en "lucha contra el comunismo". En ese contexto, Pereda Crespo robó los expedientes psicológicos de los consejeros universitarios acusados de "rojos", no obstante, fue descubierto, detenido, expulsado de la universidad y a pesar de la gran movilización de sus compañeros de militancia, estuvo preso durante un año. El 25 de enero 1971, fundó en el Estado de México, la Sociedad Cruzados de Cristo Rey, un tiempo después, se convirtieron en consejeros espirituales del ejército mexicano. (González 2003: 374; Santiago 2016: 85, 111-112).

56 Teólogo francés fundador de la organización Cité Catolique en 1946, su medio de difusión y formación doctrinal fue la revista Verbe. Postuló la necesidad de crear una élite católica que pudiera modificar a la sociedad.

57 Escritor nacionalista, egresado como abogado de la Universidad Nacional de La Plata en 1960. Se desempeñó como docente en la Universidad Nacional de Cuyo. (Orbe 2016)

58 Resolución del Rectorado de la Universidad de Salta No. 508-80. 


\section{Mónica Alcántara Navarro}

serían "una verdadera propuesta de integración Hispanoamericana sobre los principios de la Doctrina de Iglesia".

\section{Conclusiones}

En las reuniones transnacionales de las que dio cuenta este artículo texto, se percibe a los jóvenes intransigentes como asistentes, organizadores, coordinadores, conferencistas, discutiendo con sus pares de otros países, haciendo viajes nacionales e internacionales para establecer contactos o consolidarlos, dialogando con adultos laicos o de la jerarquía eclesiástica. Al mismo tiempo eran estudiantes universitarios y parte de la militancia estudiantil vinculada al catolicismo. Las universidades fueron los espacios de actividad militante, desde las cuales deseaban contribuir a la recristianización de Hispanoamérica.

Sin embargo, la prensa nacional, las publicaciones católicas revisadas y la documentación de espionaje, les prestan poca atención. Los datos sobre los congresos se registran con la intención de plasmar la capacidad de articulación internacional de los católicos o para denunciarlos, en cambio, los jóvenes aparecen únicamente cuando un adulto (intelectual laico o integrante de la jerarquía) o una institución le impregna un valor a sus actividades y a sus espacios de reunión. Entre las dificultades que presentan las fuentes para el estudio de los jóvenes católicos es que reproducen las aspiraciones arquetípicas de los adultos laicos o de la jerarquía sobre la militancia juvenil, que apuntaba a una participación despolitizada y dócil de los jóvenes. Existen escasos registros sobre sus posturas o discusiones políticas y son mencionados cuando secundan la opinión de un adulto, dando la impresión de reafirmaran la falta de tutelaje.

Más allá de las complicaciones con las fuentes, esas características son un indicador de las tensiones en torno a la definición del joven católico y su papel en las universidades y en los proyectos transnacionales de consolidación de las naciones hispanoamericanas.

A pesar de las palabras de aliento del Papa y del reconocimiento de la juventud católica ocurrido desde el Concilio Vaticano II, lo que expresan sectores católicos son posturas que desconfían sobre su "fuerza renovadora". En el caso argentino, su integración al "Proceso" tendría que ser bajo el tutelaje intelectual y espiritual de los adultos, para evitar el riesgo de la "desviación marxista". Los adultos, los veían con cierto recelo y preferían mantener tuteladas sus actividades. Esto abre diversas interrogantes sobre cómo o quiénes construyeron los significados en torno a ser un joven católico frente al mundo de los adultos. 


\section{El Consejo Hispanoamericano de Estudiantes (1979-1980). La juventud católica intransigente en la Guerra Fría}

\section{Referencias bibliográficas}

Acha, 0. (2016). "La rama masculina juvenil de la Acción Católica Argentina: catolicismo y política asociativa (1931-1970)", Revista Brasileira de História das Religiões; vol. 9.

Aguilar, H. y Meyer L. (2000). A la sombra de la Revolución Mexicana. Cal y Arena: Ciudad de México.

Alcántara, M. (2016). Cúcara Mácara, el MURO fue. Del Pacto de los Remedios, a la Virgen del Siquitibum, Tesis de licenciatura, Ciudad de México, Universidad Nacional Autónoma de México.

Aspe, M. L. (2007). La formación social y política de los católicos mexicanos. La Acción Católica Mexicana y la Unión Nacional de Estudiantes Católicos, 1929-1958, Ciudad de México, Universidad Iberoamericana.

Blancarte, R. (1994). Historia de la Iglesia Católica en México, 1929-1989, Ciudad de México, Fondo de Cultura Económica.

Blanco, J. (2001). “Las distintas juventudes en la Iglesia Argentina a mediados del siglo XX. Los casos de la Juventud de Acción Católica y Juventud Obrera Católica" en Letras Históricas, Universidad de Guadalajara, №4, año 3, México, pp. 139-160. Disponible en: http://www.publicaciones.cucsh.udg.mx/pperiod/Lhistoricas/pdfs/vol4/6.pdf [Consulta: 17/10/2018].

Bohoslavsky, E. y Gomes, G. (2016). "La otra juventud radicalizada. El anticomunismo en Argentina y Chile (1959-1973)", Oficina do Historiador, Vol. 9, $\mathrm{N}^{\circ}$ 1, PUCRS, Porto Alegre, pp. 38-57. Disponible en: < https://www.academia.edu/26880595/La otra juventud radicalizada. El antico munismo en Argentina y Chile 1959-1973 >. [Consulta: 18/10/2018].

Bohoslavsky, E. y Vicente, M. (2014). “'Sino el espanto'. Temas, prácticas y alianzas de los anticomunismos de derecha en Argentina entre 1955 y 1966". Anuario del Instituto de Historia Argentina, No. 14. Disponible en https://www.anuarioiha.fahce.unlp.edu.ar/article/view/IHAn14a11 [Consulta: 5/11/2010].

Briceño, C. (2014). "La frontera Chilena-Argentina: La controversia por el Canal del Beagle", Tiempo y Espacio, vol. 24, No. 62, Caracas. Disponible en http://www.scielo.org.ve/scielo.php?script=sci arttext\&pid=S131594962014000200012 [Consultado: 20/11/2018] 
Carnagui, J. (2016). Nacionalistas, católicos y peronistas. Auge, afianzamiento y reconfiguración de la Concentración Nacional Universitaria (CNU) La Plata 19551974, Tesis de doctorado, Universidad Nacional de la Plata. La Plata.

Cedillo, A. (2010). El suspiro del silencio. De la reconstrucción de las Fuerzas de Liberación Nacional a la Fundación del Ejército Zapatista de Liberación Nacional (1974-1983). Tesis de Maestría. Ciudad de México, Universidad Nacional Autónoma de México.

Cersósimo, F. (2014). “Por la instauración de la 'Nación Católica'. La formación Moral y Cívica durante la gestión del ministro Juan Rafael Llenera Amadeo (1978-1981)", en: Clío \& Asociados. Universidad Nacional del Litoral-Universidad Nacional de la Plata. Disponible en: http://sedici.unlp.edu.ar/bitstream/handle/10915/47513/Documento completo. pdf?sequence $=1$ [Consultado: 10/10/2018].

Córdova, A. (1979). "Reforma política y reforma económica en el México Actual". Investigación Económica, vol. 38, No. 150, Facultad de Economía, Universidad Nacional Autónoma de México, pp. 449-466. En < https://www.jstor.org/stable/42870789?seq=1\#page scan tab contents> [Consultado: 25/11/2018]

Dávila, N. (2001). Las Santas Batallas de Anticomunismo en Puebla, , Gobierno del Estado de Puebla/Benemérita Universidad Autónoma de Puebla: México.

Delgado, A. (2004). El ejército de Dios. Nuevas revelaciones sobre la extrema derecha en México.Ciudad de México: Plaza Janés.

Díaz Porcellana, J. (2013). "La reconstrucción de la juventud. Aproximación al concepto de juventud elaborado por el Episcopado argentino durante la transición democrática (1981-1985)", ponencia presentada en XIV Jornadas Interescuelas de Historia, Mendoza.

Fernández, N. (1978). "La reforma política: orígenes y limitaciones". Cuadernos políticos, No. 16, Editorial Era. En < http://www.cuadernospoliticos.unam.mx/cuadernos/contenido/CP.16/CP16.4.Nu riaFernandez.pdf> [Consultado: 24/11/18].

González, E. (2003). MURO, memorias y testimonios 1961-2002. Gobierno del Estado de Puebla/Benemérita Universidad Autónoma de Puebla: Puebla.

Herrán Ávila, L. (2015). "Las guerrillas blancas: anticomunismo transnacional e imaginarios de derechas en Argentina y México, 1954-1972". Quinto Sol. Vol. 19, No. 1.

$<$ https://www.academia.edu/12171756/Las guerrillas blancas anticomunismo t 


\section{El Consejo Hispanoamericano de Estudiantes (1979-1980). La juventud católica intransigente en la Guerra Fría}

ransnacional e imaginarios de derechas en Argentina y México 19541972 "s de derechas en Argentina y M\%C3\%A9xico 1954-1972

Lida, M. (2008). “Las masas católicas en los años de la dictadura, 1976-1982” en: Entrepasados, No. $34 . \quad$ Disponible en < http://historiapolitica.com/datos/biblioteca/lida cyp.pdf> [Consultado: 20/10/2018].

López, M. (2010), “La historia de una colaboración anticomunista transnacional. Los Tecos de la Universidad Autónoma de Guadalajara y el gobierno de Chiang Kai-Shek a principios de los años setenta". en: Contemporánea. Historia y problemas del siglo $X X$, Vol. 1, año 1, disponible en http://www.geipar.udelar.edu.uy/wpcontent/uploads/2012/05/09 Dossier07.pdf [Consulta: 20/10/2018].

Manzano, Valeria. La era de la juventud en Argentina. Cultura, política y sexualidad desde Perón hasta Videla. Ciudad Autónoma de Buenos Aires, Fondo de Cultura Económica, 2017.

Medina, L. (2010). Hacia el nuevo Estado. México, 1920-2000. Fondo de Cultura Económica: Ciudad de México.

MINTZ, S. (2008). "Reflections on age as a category of historical analysis", Journal of the History of Chilhood and Youth, The Johs Hopkins University Press, v. 11.

Pattin, S. (2018). Entre Pedro y el pueblo de Dios. Las concepciones de autoridad en el catolicismo argentino (1962-1976). Prohistoria ediciones: Rosario.

Puente Lutteroth, M. (2002). Movimiento cristero: una pluralidad desconocida, Editorial Progreso: México.

Rodríguez, L. (2011). “Los nacionalistas católicos de Cabildo y la educación durante la última dictadura en Argentina", en: Anuario de Estudios Americanos, Vol. 1, № 68, Sevilla, Disponible

en http://estudiosamericanos.revistas.csic.es/index.php/estudiosamericanos/article Lview/539/. [Consulta: 10/10/2018]

Rodríguez, L. (2015). Universidad Peronismo y Dictadura 1973-1983. Prometeo Libros: Buenos Aires.

Rodríguez, L. (2016). “La 'subversión científica' en las universidades de Argentina e Hispanoamérica". en: Nuevo Mundo Mundos Nuevos. Disponible en http://nuevomundo.revues.org/68862 [Consulta: 15/10/2018].

Rodríguez, L. y Barbarito, M. (2011). "Los católicos de derecha en los años sesenta. La experiencia 'comunitarista' en Pergamino (1966-1973)”. Ponencia presentada en las III Jornadas Nacionales de Historia Social, La Falda, Argentina. Disponible en: 


\section{Mónica Alcántara Navarro}

Memoria

Académica

http://www.memoria.fahce.unlp.edu.ar/trab eventos/ev.9772/ev.9772.pdf > [Consultado: 31/10/2018].

Rostica, J. (2017). "La Confederación Anticomunista Latinoamericana. Las conexiones civiles y militares entre Guatemala y Argentina (1972-1980)". Desafíos, Vol. $1, \quad \mathrm{~N}^{\circ} \quad 30 . \quad$ Disponible en http://dx.doi.org/10.12804/revistas.urosario.edu.co/desafios/a.5227 . [Consulta: 15/10/2018].8

Santiago, M. (2012). Anticomunismo católico. Raíces y desarrollo del Movimiento Universitario de Renovadora Orientación (MURO), 1962-1975. Tesis de maestría, Instituto de Investigaciones Dr. José María Luis Mora, Ciudad de México.

Santiago, M. (2016). Entre el secreto y las calles. Nacionalistas y católicos contra la 'conspiración de la modernidad': El Yunque de México y Tacuara de Argentina (19531964). Tesis de Doctorado, Instituto de Investigaciones Dr. José María Luis MoraCiudad de México.

Schindel, E. (2005). "El sesgo generacional del terrorismo de Estado: niños y jóvenes bajo la dictadura argentina (1976-1983)". En Potthast, B. y Carreras, S., Entre la familia, la sociedad y el Estado. Niños y jóvenes en América Latina (siglos XIX-XX). Iberoamericana-Vervuert: Madrid-Frankfurt.

Scirica, E. (2010). "Visión religiosa y acción política. El caso Ciudad Católica-Verbo en la Argentina de los años sesenta". PROHAL Monográfico, revista del Programa de Historia de América Latina, Vol. 2, №. 2, Instituto Ravignani, Facultad de Filosofía y Letras, Universidad de Buenos Aires, pp 26-56.

Villar, A. (2014). "El desconocido papel de Estados Unidos en la crisis del Canal del Beagle”, Estudios Internacionales, Vol. 46, No. 178. Instituto de Estudios Internacionales-Universidad de Chile. Disponible en https://revistaei.uchile.cl/index.php/REI/article/view/32515 [Consultado: 28/11/2018].

Zurita, M. (2010). "El conflicto del Beagle desde la perspectiva del diario La Nación”, Question. Revista Especializada en Periodismo y Comunicación, vol. 1, No. 25. Universidad Nacional de La Plata. Disponible en < https://perio.unlp.edu.ar/ojs/index.php/question/article/view/917/817> [Consultado: 25/11/2018].

\section{Fuentes}

Archivo General de la Nación 


\section{El Consejo Hispanoamericano de Estudiantes (1979-1980). La juventud católica intransigente en la Guerra Fría}

Archivo de la Dirección Federal de Seguridad

Archivo de la Dirección de Inteligencia de la Policía de la Provincia de Buenos Aires

Hemerografía:

México: Unomásuno

El Día, El vocero del Pueblo Mexicano

El Universal

Proceso

Argentina: La Voz del Interior

Los Principios

La Nación

Clarín

Cabildo

España: ABC [en línea]

Resoluciones del rectorado de la Universidad de Salta:

http://bo.unsa.edu.ar/dr/R1980/R-DR-1980-0508.pdf

http://bo.unsa.edu.ar/dr/R1980/R-DR-1980-0509.pdf

http://bo.unsa.edu.ar/dr/R1980/R-DR-1980-0596.pdf

Testimonio

Directivo (seudónimo). Entrevista realizada por Mónica Alcántara Navarro, Ciudad de México, 8 de junio del 2015.

Recibido: 01/02/2019

Evaluado: 23/02/2019

Versión Final: 17/03/2019 